Article

\title{
Public Support for Sustainable Welfare Compared: Links between Attitudes towards Climate and Welfare Policies
}

\author{
Martin Fritz ${ }^{1, *}$ and Max Koch ${ }^{2}$ \\ 1 Junior Research Group “Mentalities in Flux" (flumen), Institute of Sociology, Friedrich Schiller University \\ Jena, Humboldtstraße 34, 07743 Jena, Germany \\ 2 Socialhögskolan, Lund University, Box 23, 22100 Lund, Sweden \\ * Correspondence: martin.fritz@uni-jena.de
}

Received: 27 June 2019; Accepted: 30 July 2019; Published: 1 August 2019

\begin{abstract}
The emerging concept of sustainable welfare attempts to integrate environmental sustainability and social welfare research. Oriented at a mid-term re-embedding of Western production and consumption norms into planetary limits, it suggests the development of "eco-social" policies in the rich countries. In this theoretical context, this article empirically investigates the relationships between attitudes towards welfare and climate policy in 23 countries. Using 2016 data from the European Social Survey, we explored patterns of synergy between both kinds of policies as well as effects of crowding-out, where support for one kind of policy involves refusing the other. Since previous research addressed the role of welfare states and their institutional foundations in establishing environmentally sustainable societies, we studied how attitudes towards welfare and climate policies differ according to welfare regime affiliation. Additionally, we examined how a range of socio-demographic and political factors such as class, education, income, and political position shape people's views on welfare and climate policy goals. The results of a multiple correspondence analysis indicate that the simultaneous support of welfare and climate policies follows welfare regime lines in that this support is the highest among social-democratic countries. However, also some conservative and Mediterranean countries score high in this regard. At the individual level, people with a higher education, employees in socio-cultural professions, and voters of moderate left and green parties display the highest mutual support for welfare and climate policies.
\end{abstract}

Keywords: climate change; climate policy; social policy; sustainable welfare; attitudes; environmental policy; energy preferences; welfare; eco-social policies; European Social Survey

\section{Introduction}

Climate policy targets such as those identified in the Paris Agreement have distributional repercussions that threaten to make them unpopular with the electorate. These distributional effects have been addressed in theories of climate justice and in models of burden sharing between rich and poor countries [1]. Yet, such effects feature also within the rich countries and affect the feasibility of decarbonization strategies in economically advanced democratic societies. Different societal groups have different responsibilities for climate change, and experience different impacts. Often responsibilities and impacts work in opposite ways, constituting a "double injustice" [2], since the groups likely to be affected by climate change are the least responsible for causing it. The poor emit the lowest amounts of greenhouse gases compared to richer countries and household groups, but are nevertheless hit first and hardest by climate change. If rich countries and, within the rich countries, richer household groups, continue to pay less than what climate expertise regards as necessary, this 
may even turn into a "triple injustice" [3] since the poor have the least resources to bear the financial burden of climate policies. For example, low-income households spend a relatively high proportion of their income on energy-intensive activities such as heating and/or cooling and would be affected the most by a general rise in energy tariffs [4].

A growing body of literature [5,6] argues that qualitatively different welfare policies than those that emerged in the post-World War II context would be necessary to counteract the distributional consequences of climate policies. An alternative eco-welfare governance network would need to redistribute not only carbon emissions, but also work, time, income and wealth [7]. Not only will social policies need to address the inequalities and conflicts that are likely to emerge during decarbonization processes of production and consumption patterns [8], it will also be increasingly necessary to formulate them in ways that create synergy with environmental goals and that are acceptable to the electorate. If welfare and climate goals and policies are to converge, a better understanding of what drives attitudes both in the spheres of welfare/social policy and climate/environmental policy than currently is necessary to develop corresponding policy strategies. Especially uncovering the ways and extent to which the two spheres interact would provide policymakers, who aim to act in public responsibility, with essential knowledge about what kind of eco-social policies may be acceptable to voters without risking to be voted out at the next opportunity. Of equal relevance is the role of institutional particulars and how attitudes may vary according to welfare regime affiliation and socio-demographic and political factors such as class, education, political and religious orientation. Using 2016 data from the European Social Survey (ESS), this article contributes to the provision of this kind of knowledge by comparatively investigating attitudes to both welfare and climate policies, how they interact and what kind of socio-demographic and political factors are supportive for corresponding eco-social policy strategies.

This paper is structured as follows: In the remaining two sections of the introduction, it presents the theoretical sustainable welfare approach and formulates the research questions. Subsequently, it reports on the empirical materials, sources, and methods and summarizes the comparative results. The discussion highlights the main findings and outlines further research corridors.

\subsection{Sustainable Welfare}

Despite the necessity of linking welfare and climate policies, there has, until recently, been a lack of theorizing of the intersection of welfare and social policy, on the one hand, and climate change and the environment, on the other. Instead, scholars have tended to carry out research into social welfare and environmental sustainability without much cross-fertilization. Welfare is commonly conceptualized in socio-economic terms, highlighting equity and distributive issues within growing economies in terms of Gross Domestic Product (GDP), while social policy is often conceived as the "public management of social risks" such as ill-health or unemployment [9]. Environmental concerns, which were raised as early as the 1970s [10], keep largely being ignored in social policy debates [11]. Although much recent research suggests that one cannot generalize Western production and consumption standards to the rest of the world due to ecological and planetary limits $[12,13]$, neither policymakers nor welfare scholars have paid much attention to the relevance and potential implications of environmental sustainability issues for social policy and welfare theory [14].

This began to change with the growing awareness that major threats to human welfare transcend both space and time. Climate change is a good example of a transnational and transgenerational phenomenon: greenhouse gases emitted here and now mix with the existing stock of greenhouse gases in the atmosphere, thereby producing global warming and amplifying the risk of negative effects such as droughts and flooding that are dispersed over time and space, that is, including in those geographic zones where the greenhouse gases were not emitted and in the decades to come.

The emerging concept of "sustainable welfare" [6], developed in interdisciplinary cooperation mainly at Lund University, recognizes the transcendent character of contemporary activities, and, accordingly, raises normative questions such as whose welfare should be represented in actual welfare 
societies. Brandstedt and Emmelin [15] argue that the distributive principles underlying existing welfare systems would need to be extended to include those affected in other countries and in the future. Any actual welfare provision would need to consider that the satisfaction of present welfare demands should not undermine the ability of future generations to meet their welfare needs. This includes the recognition of critical thresholds and limitations and also that needs, aspirations, and wants must be reviewed-and possibly restrained —in order not to violate what Langhelle [16] calls the "sustainability proviso". In short, the ambition of "sustainable welfare" is to identify the means and ways to satisfy human needs within environmental limits, everywhere on the planet and across generations [6]. Addressing intergenerational concerns and issues of universality in the context of climate change, Gough [7] suggests a "policy auditing" principle for a "minimally decent life", which constantly (re-)defines critical thresholds in light of the advancement of academic and practical knowledge. While it is, in principle, possible to satisfy basic human needs on a global scale, the degree to which more than basic needs can be provided on a planet with finite resources remains subject to scientific inquiry [17]. In contrast to the Sustainable Development Goals (SDGs), most "sustainable welfare" authors are doubtful that this can be achieved while promoting economic growth at the same time. In fact, according to Koch and Buch-Hansen [18], the sustainable welfare approach may be best understood as a sub-discipline of the wider degrowth/post-growth perspective [19-21], specializing on the relationship and interaction of welfare and sustainability.

"Sustainable welfare" may also constitute a theoretical and normative framework for redesigning existing policies in an "eco-social" direction. As also recognised by the SDGs, achieving the Paris climate targets will require greater coordination of welfare and climate policies. A range of eco-social policy proposals [22] exist. Integrated into a comprehensive policy strategy, these have the potential to bring about a redistribution of carbon emissions, work, time, income and wealth in the rich countries. Scholars such as Daly and Farley [23], Jackson [24] and Gough [7] regard such redistribution as indispensable for a re-embedding of Western production and consumption levels into planetary levels [25], while allowing development space for poorer countries.

One way of democratically steering a re-embedding of societal production and consumption processes into planetary limits is an application of the "dual strategy" [7], which was designed to integrate the codified knowledge of "experts" and the experimental and practical knowledge of citizens. Accordingly, citizens, experts, government and civil society representatives would work together in democratic and deliberative forums to identify the goods and services necessary for needs satisfaction within a particular social and cultural context and environmental limits [18].

Hence, the understanding of climate change as a "wicked problem" [26], in particular, and the very idea of environmental sustainability, in general, is a challenge to business as usual for public policymaking and has significant implications for the scope and direction of welfare policies in particular, which would need to give a greater weight to distribution and justice across nations and generations. In "sustainable welfare", the central welfare concern is not the provision with and distribution of material riches for the "happy few" in Western societies but rather the satisfaction of basic needs for all humans now and in the future $[6,18]$.

\subsection{Research Questions}

This brief literature overview indicates that if ambitious climate and other environmental policies are to be acceptable to the electorate they have to be combined with targeted social policies to counteract the double or even triple injustice of climate change (see above). To achieve greater compatibility between welfare and climate policies in democratic societies and initiate effective eco-social policies, knowledge about existing attitudes among the electorate towards both welfare and climate policies and their interrelations is crucial. Jakobsson et al. [27] used data from the International Social Survey Programme to comparatively study attitudes towards environmental and welfare policies at the example of people's willingness to pay for environmental protection on the one hand and, on the other, for reducing social inequalities. In this paper, we explored welfare and climate policy attitudes 
in 23 countries as to whether these diverge or converge. To the former, Jakobsson et al. [27] (p. 4) referred in terms of crowding-out: Climate-related and social concerns are substitutes, that is, people who prioritize climate policy are less concerned about social inequality and related welfare issues and policies or vice versa. The latter would constitute what Jakobsson et al. call "double worry": Since people who are concerned with traditional social issues and policies also worry about the climate, there is synergy between their attitudes towards both kinds of policies. We also opened up for the possibility that people neither care about the climate nor welfare.

In addition, we aimed to further contribute to the debate on the relationship between welfare regimes $[28,29]$ and environmental performance by comparatively studying peoples' attitudes on welfare and climate change. Originally, Gough et al. [9] expected that countries with a social-democratic welfare regime, which have proven to be more equal in socio-economic terms than conservative and liberal ones, would also perform best on environmental sustainability indicators. However, subsequent studies $[27,30,31]$ could not confirm any link or synergy between countries" welfare regime affiliation and environmental performance. Yet, this does not necessarily rule out the possibility that the institutional potentials of social-democratic welfare states to initiate eco-social policies and, eventually, build eco-social states may have as yet been under-utilized. In this case, there would be a gap between what people would like to see in terms of sustainable welfare and eco-social policies and what is actually been provided by policymakers. Dryzek [9] (pp. 334-335), for example, emphasized that the discourse on ecological modernization and climate change would be especially widespread in social-democratic welfare regimes. From this, the hypothesis would follow that the simultaneous support of welfare and climate policies is greatest in countries with this welfare regime affiliation. We, therefore, studied if welfare and climate attitudes of citizens in 23 countries vary according to welfare regime lines. We finally considered a range of socio-demographic and political factors that may make citizens more or less amenable for a convergence of climate and welfare policies.

\section{Materials and Methods}

We used data from the European Social Survey (ESS) [32], a cross-national survey conducted biannually as face-to-face interviews to measure attitudes, beliefs and behavioral patterns among citizens. In 2016, respondents in 23 countries (see Table 1) answered questions about their opinions on climate change and social welfare issues at the same time. This allowed for a comparative analysis of whether and how environmental and social attitudes are interrelated at the individual level.

Table 1. Sample sizes of the European Social Survey 2016 by country.

\begin{tabular}{cccc}
\hline Country & Sample Size (n) & Country & Sample Size (n) \\
\hline Austria & 2010 & Lithuania & 2122 \\
Belgium & 1766 & Netherlands & 1681 \\
Czech Republic & 2269 & Norway & 1545 \\
Estonia & 2019 & Poland & 1694 \\
Finland & 1925 & Portugal & 1270 \\
France & 2070 & Russian Federation & 2430 \\
Germany & 2852 & Slovenia & 1307 \\
Hungary & 1614 & Spain & 1958 \\
Iceland & 880 & Sweden & 1551 \\
Ireland & 2757 & Switzerland & 1525 \\
Israel & 2557 & United Kingdom & 1959 \\
Italy & 2626 & Total & 44,387 \\
\hline
\end{tabular}

Our analyses are based on the variables of altogether five item batteries that operationalize different aspects of attitudes towards climate and welfare policies (see Table 2). Attitudes towards climate policies were operationalized by two sets of variables: 
Table 2. Overview of concepts and variables.

\begin{tabular}{ccc}
\hline Attitudes & Item Battery & Number of Variables \\
\hline climate policy & energy preferences & 7 \\
& policy instruments & 3 \\
welfare & role of government & 3 \\
& social benefits & 6 \\
& social justice & 2 \\
& Total & 21 \\
\hline
\end{tabular}

First, people's energy choices and preferences reflect the divide between "green" and "brown" industries and indicate whether there is a general willingness to use more climate-friendly generated energy. Accordingly, in the ESS 2016 energy preferences were distinguished between renewable and fossil forms of energy. Specifically, respondents were asked: "How much of the electricity used in [country] should be generated from coal [natural gas, hydroelectric power of flowing water, nuclear power, solar power, wind power, and biomass energy]?" [33] (pp. 31-32). Answers were given on a five-point Likert-scale ranging from "a very large amount" over "a medium amount" to "none at all". Second, people were asked to give an evaluation of three different climate policy instruments: increasing taxes on fossil fuels, subsidizing renewable energy, and a law banning the least energy-efficient household appliances. The respondents' ratings of these climate policy instruments were again reflected in the format of a five-point Likert-scale from "strongly in favor" via "neither in favor nor against" to "strongly against".

People's opinions about welfare were measured by three sub-concepts: First, we investigated attitudes towards the welfare state; specifically, whether governments should have to ensure a reasonable standard of living for the old and for the unemployed as well as to provide sufficient childcare services for working parents. Here, answers varied on a 0-10 scale between "should not be governments" responsibility at all" and "should be entirely governments" responsibility". Some of the categories of the 0 to 10-point scale had very low frequencies that would distort the analyses and graphical visualizations as extreme outliers. Thus, we grouped these categories in order to be included in the analysis. The old categories $0-4$, which had the lowest frequencies-in some cases less than one percent, were recoded into $1=$ the government is not responsible, categories $5-7$ into $2=$ the government is somewhat responsible, categories 8 and 9 into $3=$ the government is responsible a great deal, and the old category 10 , which has very high frequencies, into the new category $4=$ the government is entirely responsible. Second, the core idea of welfare is to assist people coping with social risks such as illness or unemployment via the use of social benefits and services. Respondents could evaluate six statements about the perceived social and economic consequences of these social policy instruments:

"... to what extent you agree or disagree that social benefits and services in [country] ...

1. Place too great a strain on the economy?

2. Prevent widespread poverty?

3. Lead to a more equal society?

4. Cost businesses too much in taxes and charges?

5. Make people lazy?

6. Make people less willing to care for one another?" [33] (pp. 40-41)

Again, the statements were evaluated on a five-point Likert-scale from "agree strongly" via "neither agree nor disagree" to "strongly disagree". Third, welfare and social policy are guided by ethical principles regarding the justification of how resources are distributed. Considering this social justice dimension of attitudes towards welfare, we included respondents' answers towards the following two propositions: "Large differences in people's income are acceptable to properly reward 
differences in talents and efforts", and "for a society to be fair, differences in people's standard of living should be small." [33] (p. 38). Also, these last variables were available as five-point Likert-scales.

Using the statistics software SPSS, we carried out a multiple correspondence analysis (MCA) to study the interrelations between all 21 variables and to visualize them in a map, where regions of synergy between climate and welfare attitudes can be detected and distinguished from zones of crowding-out. MCA was originally introduced to the social sciences by Pierre Bourdieu [34], who explored the links between social class and lifestyle attributes and discovered patterns of "distinction" by applying the new method. In cooperation with statistician J.-P. Benzécri [35], who published the first presentation of the technique, Bourdieu graphically displayed the results of his analyses as social fields in maps. In welfare research, the method was subsequently applied to test the appropriateness of regime typologies, to depict the multidimensionality of welfare, and to visualize relationships between countries" welfare and environmental performances [30,36,37].

Essentially, MCA is a technique of data analysis that identifies the latent relationships between variables and represents them graphically in a two-dimensional Euclidean space [38]. It is similar to Principal Component Analysis (PCA), a method that also computes latent relationships. However, PCA is based on correlations and these cannot meaningfully be calculated for nominal and ordinal variables. $\mathrm{MCA}$, in contrast, as an exploratory technique is based on the frequencies of cells in cross-tabulations and therefore suitable for the analysis of associations between two or more categorical variables such as our Likert-scale items in the ESS 2016. The starting point for our MCA was the Burt table containing all two-way cross-tabulations between the 21 variables. The positions of countries and socio-demographic and political factors were added as supplementary points (sometimes also referred to as passive variables) in the map in order to display their relation to climate and welfare attitudes [39] (p. 74). In PCA terminology, these would be the scores by country and sociodemographic characteristics. The categories of the climate and welfare variables were used in the MCA to actively unfold the space of the map. Following Bourdieu, they are displayed as points in an "eco-social field" whereby the distances between them are interpreted as similarities: The closer two category points are located in the map the more similar and associated they are to each other. And, vice versa, if two category points are located relatively far from each other, they are very dissimilar and not associated.

\section{Results}

An overview of the numerical results of the MCA applied to the data of all 23 countries is presented in Table 3. The first three dimensions altogether account for 71 percent of the variance, whereby the first dimension has an explanatory power of 45 percent. We show the graphical output of the MCA for the first and the second dimension, since they capture the main substantial information and patterns of climate and welfare attitudes.

Table 3. Results of the Multiple Correspondence Analysis.

\begin{tabular}{ccccc}
\hline \multicolumn{5}{c}{ Summary of Multiple Correspondence Analysis (n=44,352) } \\
\hline Dimension & $\begin{array}{c}\text { Cronbach's } \\
\text { Alpha }\end{array}$ & Eigenvalue & $\begin{array}{c}\text { Adjusted Inertia Using } \\
\text { Benzécri's [39] (p.68) Method }\end{array}$ & $\begin{array}{c}\text { \% Explained } \\
\text { Variance }\end{array}$ \\
\hline 1 & 0.8 & 4.1 & 0.0241 & 45.1 \\
2 & 0.7 & 2.8 & 0.0078 & 14.5 \\
3 & 0.6 & 2.6 & 0.0060 & 11.3 \\
Total (Dim. 1-31) & - & 47.5 & 0.0534 & 100.0 \\
\hline
\end{tabular}

To improve the readability of the subsequent maps, all climate-related variables are displayed in blue, while welfare variables appear in black. Moreover, in Figure 1 we did not include the labels for the single points in order to keep the map clearly arranged and readable. Instead, we added circles and ellipses around those category points which measure the same degrees of agreement or disagreement. While they do not represent confidence intervals or any other statistical parameter, we inserted these 
geometrical structures as graphical aid in order to easily detect the areas of synergy and crowding-out within the eco-social field. All maps were created with the software Excel.

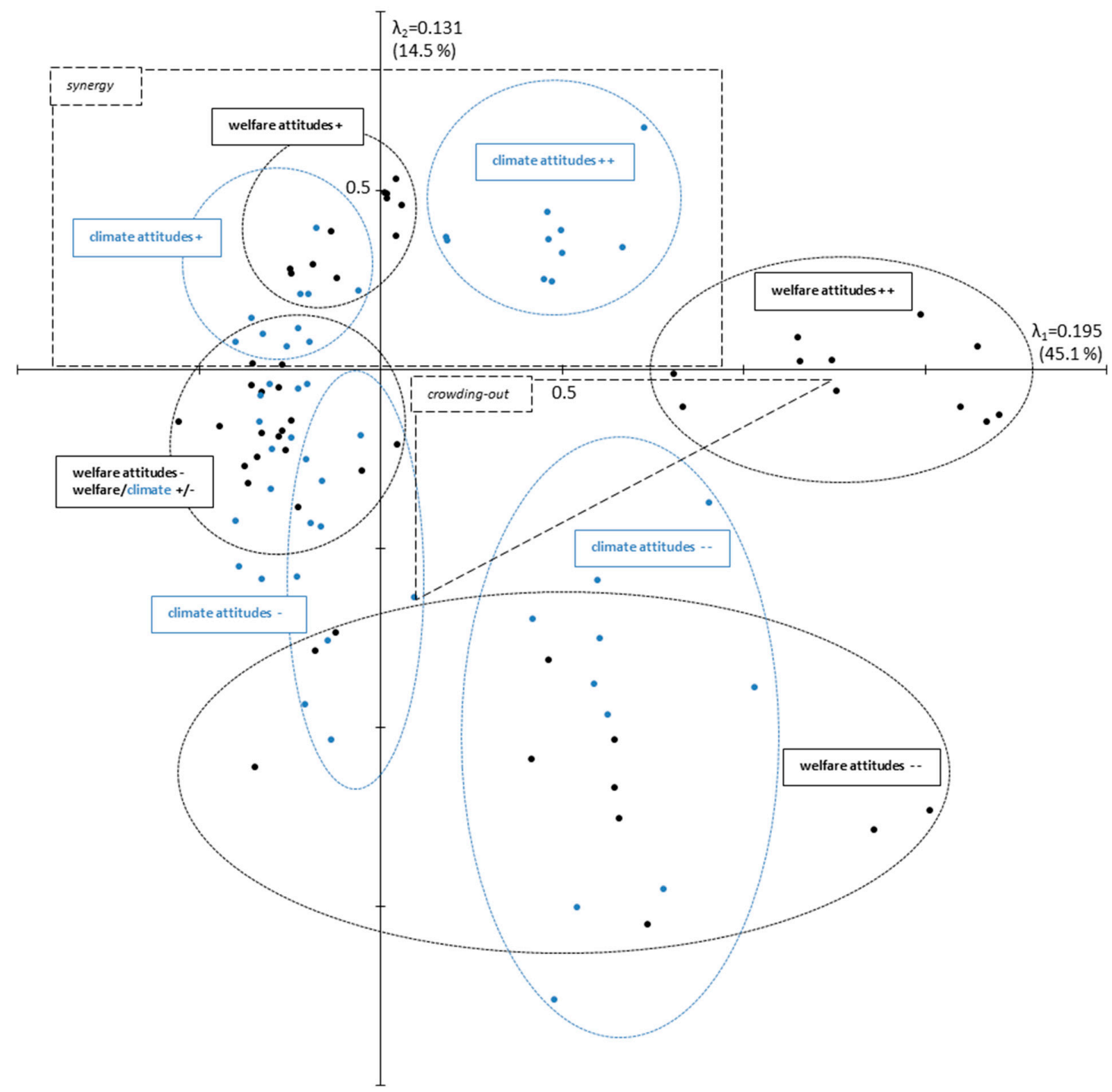

Figure 1. Climate and welfare attitudes.

The horizontal axis displays moderate climate and welfare attitudes on the left side, where we see the points for the neutral categories (+/-) of the five-point Likert-scales as well as the points for moderate agreement $(+)$ and disagreement $(-)$. Conversely, we find the points for strong agreement $(+$ $+)$ and strong disagreement $(--)$ on the right side of this axis. Thus, the first dimension illustrates the differences between the respondents" answering behavior. These are most pronounced for the welfare variables as they appear at the very outer parts of the axis. The second dimension represents the contrast between pro-climate and pro-welfare attitudes in the upper area and the rejection of climate and welfare-friendly statements in the lower sectors of the map. Overall, a pattern emerged that indicates a huge overlap between both kinds of attitudes: positive and negative climate and welfare attitudes are closely associated with each other. Exceptions are the points indicating strong agreement towards welfare statements, which are not in the same area as the points for strong agreement with climate statements. Instead they are in between strong agreement and strong disagreement of climate statements, so that respondents with a strong preference for social welfare do not necessarily also approve of climate policies. Consequentially, the area, where negative climate attitudes overlap with positive welfare attitudes, represents the pattern of crowding-out, which we displayed as the triangular 
region in the lower right quadrant of the map. The upper quadrants of the map, in which we find moderate and strong agreement with both kinds of attitudes, are, in contrast, the area of synergy, which is expressed as a rectangular space.

Hence, the MCA indicates that climate and welfare attitudes are not independent from each other and that both kinds of relationships between climate and welfare attitudes actually exist: synergy and crowding-out. The question remains, however, which individuals and which groups of individuals represent either of the two patterns. To answer this question the supplementary points of these groups are displayed in Figures 2 and 3. They represent an overall average position of all individuals belonging to the group, while the center of the map is the average position of all individuals in the data.

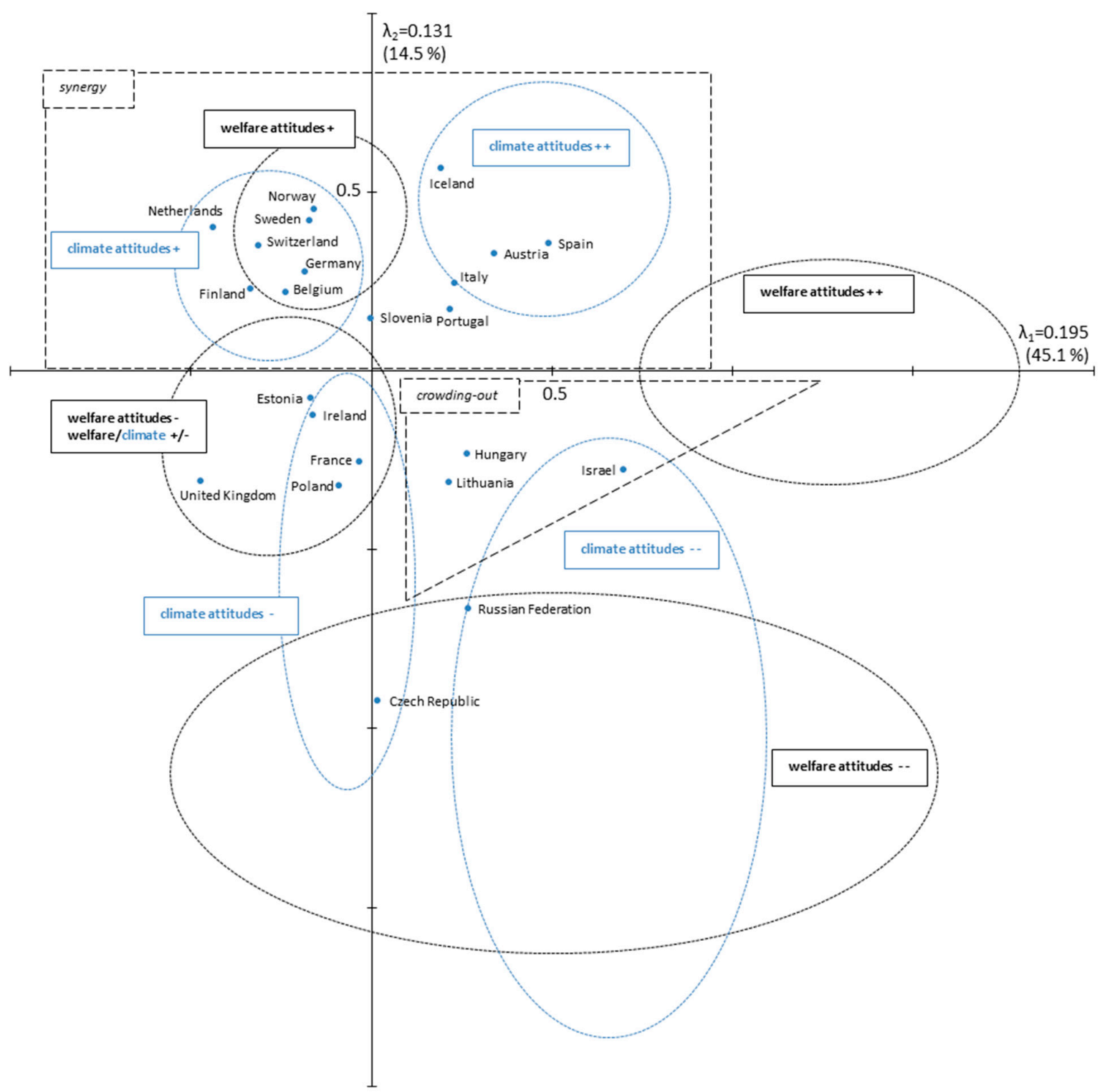

Figure 2. Countries within the space of climate and welfare attitudes. 


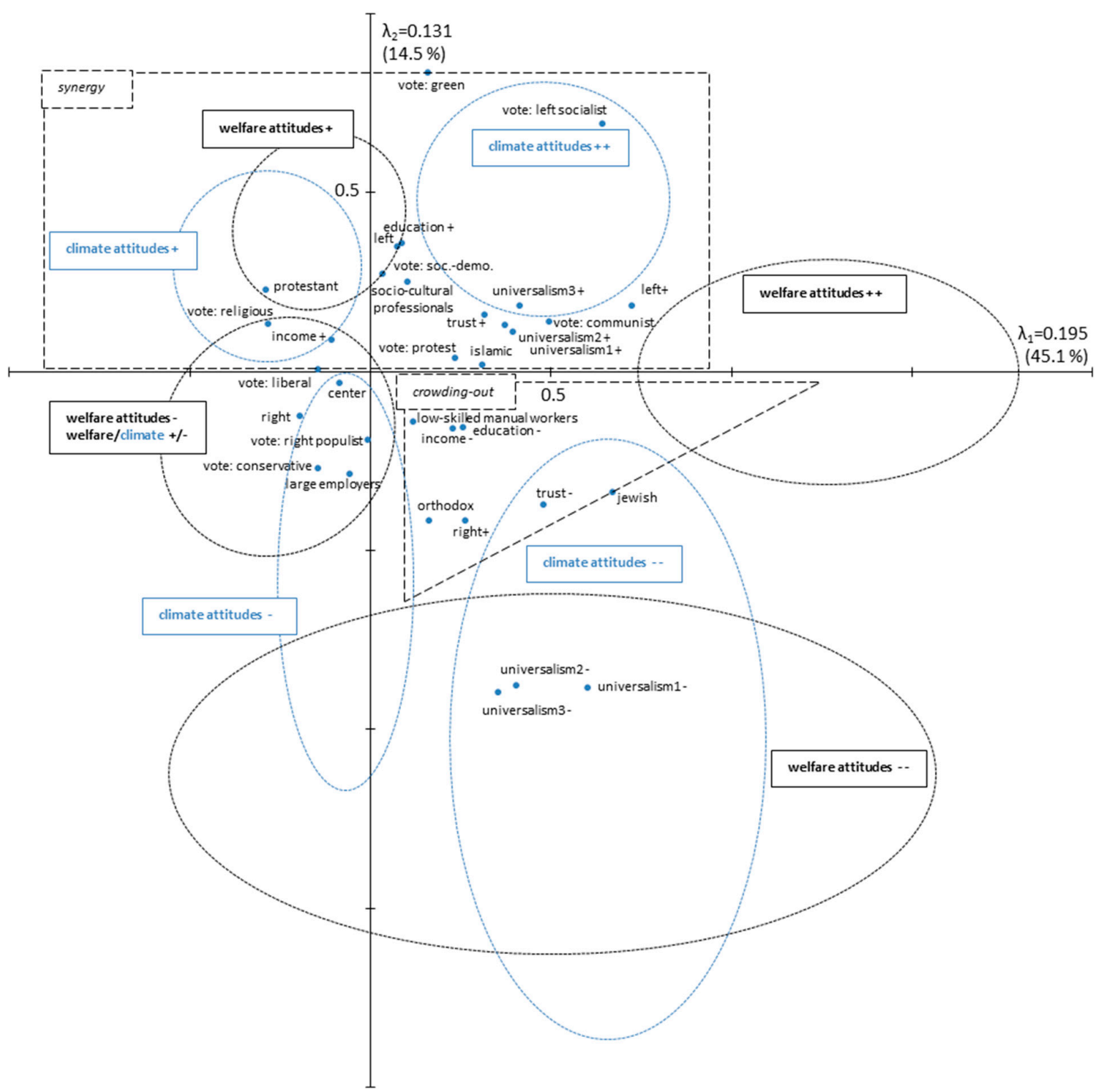

Figure 3. Socio-demographic characteristics within the space of climate and welfare attitudes.

Figure 2 reveals that people in a range of countries are open for the development and implementation of "eco-social" policies, since these countries are located in the area of synergy between climate and welfare attitudes. In Sweden, Norway, Switzerland, Germany, Belgium, Finland, and the Netherlands, people express mutual support for climate and welfare policies. In Iceland, Spain, Austria, and Italy, this synergy is even greater, since these countries are to be found in the area of strong agreement with climate statements and, at the same time, close to the points of either moderate or strong agreement with social welfare. While Slovenia and Portugal are also still located in the area of synergy they are closer to the center of the map. Hence, people in both countries do not express strong above average agreement with both kinds of policies.

In terms of welfare regimes, this group of synergy countries is diverse: It contains, as expected by Gough et al. [9], the Nordic countries with their social-democratic welfare regime, but also countries like Germany and Switzerland, which belong to the conservative regime. Other "conservative countries" such as France, however (see below) display much lower support for welfare and climate policies. In addition, we find that public opinion in Mediterranean countries such as Italy and Spain is very favorable to a combined climate and welfare policy. In contrast, the countries of the liberal regime 
and Eastern European countries express weaker support for eco-social policies or show a pattern of crowding-out.

Countries that express lower amounts of consent with climate and welfare policies are located in the lower region of the map. A first group includes the UK (despite its comparatively ambitious climate mitigation policy targets), Ireland, Poland, Estonia, and France. Here, we find a combination of low support for social welfare and average to low support for climate policies. The position of France may reflect political dissatisfaction with the previous socialist government as the fieldwork of the ESS in France was carried out between November 2016 and March 2017, directly before the first round of the presidential elections. Additionally, there is also the country's long tradition of using nuclear energy, which may well affect public opinion on climate and energy issues. The positions of Poland and Estonia can be attributed to a huge dependency on fossil energy. In both countries, there are considerable "brown" business interests due to large domestic coal resources in the case of Poland, while "... Estonia is the only country in the world in which oil shale is the primary source of energy" [40]. Thus, a huge amount of jobs depends on these fossil fuel enterprises, and people's worries about losing these jobs may be reflected in negative attitudes towards climate policies and renewable energies. In addition, the relatively negative views on welfare and social policy in Poland and Estonia may result from widespread skepticism of state interventions following experiences of communist rule. Distrust of politicians in general as well as the success of right-wing populist movements appears to go hand in hand with rather pessimistic attitudes towards the state as an actor in policymaking. We find a similar situation in the Czech Republic, which is located as the very lowest point of all countries in the map: The country has a strong coal industry and is ,... the largest net exporter of solid fuels in the EU." [40]. Moreover, a lot of jobs in the country are related to the manufacture of motor vehicles. According to Eurostat [41] more than 230,000 were employed in this branch of the economy in 2016. Because so much money and jobs in the Czech Republic depend on economic activities that still rely heavily on the use of fossil fuels, it is understandable that people disagree with policies aimed at limiting the use of coal, oil, and gas.

Finally, there are four countries within or close to the area of crowding-out in the terminology of Jakobsson et al. [27]: People in Hungary, Lithuania, Israel, and Russia favor "fossil welfare", where the moderate to high support of welfare benefits and of the welfare state in general is combined with a preference for fossil energy and a rejection of climate policies. As OECD data [40] demonstrate, two of these countries are enormously dependent on fossil energy: Israel generates 99 percent of the country's electricity from fossil fuels and Russia relies mostly on natural gas and a mix of oil, coal, and nuclear power. Renewable energy sources play a negligible role in these countries. The same data indicate that the remaining countries, Hungary and Lithuania, have decreased their dependence on fossil fuels in favor of a broader energy mix. Interestingly, their views on climate policy are more positive than in Israel and Russia but still clearly not as positive as in the rest of Europe.

\section{Socio-Demographic and Political Factors}

We included the following socio-demographic and political factors in the analysis: education (low, medium, high, very high), social class (based on employment status and occupation according to Oesch [42]), household income (low, middle, high), religious denomination, political left-right orientation and party voted for in the last national election. Here, we used party families according to Armingeon et al. [43] and classified national parties into the following groups: communist, left-socialist, green, social-democrat, center, liberal, conservative, religious, right-populist, and protest. Other categories were less frequent and therefore not depicted in Figure 3. We also tested other demographic factors such as age and gender. However, no relevant patterns emerged and the differences were too small to display them in the map.

Additionally, we show the points for respondent's generalized social trust and value orientation towards universalism. As a part of the Schwartz value circle universalism refers to the basic belief that all humans are equal and have the responsibility to protect all living beings [44] (p. 7). Universalism 
is also to some extent the value foundation of the original social-democratic welfare state [28]. The ESS 2016 includes three items measuring universalism: The first measures the belief that all people should be treated equally and have equal opportunities in life, the second measures tolerance and understanding of people that differ or even are in disagreement with the respondent, the third measures the belief that people should care for nature and the environment. We included these variables as supplementary points in Figure 3 to find out whether they are related to mutual support for climate and welfare policy. Similarly, we expected social trust to be associated with attitudes supporting both kinds of policy.

Having a high or very high education is clearly associated with simultaneous support for climate and welfare policies, while people with lower education tend to oppose climate policies with their views on social welfare being neutral. The latter group is therefore in the area of crowding-out. Concerning social class, the concept of Oesch [42] differentiates 16 class positions, which result from the combination of four hierarchical levels of employment (level of qualification) and four different work logics. Low-skilled manual workers, for example, combine a low qualification and work tasks according to a technical logic. Socio-cultural professionals, in contrast, are highly qualified and act within an interpersonal work logic. Of these 16 class positions, three are displayed in the map due to their substantial relationship with climate and welfare concepts: First, large employers (people who run a business with 10 or more employees) are more likely to reject welfare and climate policies; second, socio-cultural professionals show the highest rates of acceptance of both climate and welfare policies; third, although low-skilled manual workers are close to the center of the map, they are an example for crowding-out as their negative attitudes towards climate policies are combined with average support scores for social welfare.

While higher income households are in the synergy region - that is, they support climate and welfare policies at the same time-lower income households are to be found in the area of crowding-out. Religious denomination patterns largely resemble country differences: Most Jewish respondents live in Israel, and so the point for Jewish denomination in the map is located exactly at the same position as Israel. The same applies to people with an Orthodox denomination and the position of Eastern European countries as well as to Protestants and North-Western European countries. Catholics are too close to the center to be displayed. An interesting case, however, are Islamic respondents: Since none of the selected countries has an Islamic majority, the position in the map does not reflect a geographical pattern. Islamic respondents are just within the area of synergy with support for welfare policy and a somewhat weaker support for climate policy. Whether the reason for this finding is related to the social status of Muslims in the countries we analysed or to substantial religious reasons would be an interesting question to study in future research.

By far the most relevant and diverging factors within relations of welfare and climate policies are the respondents' political positions. Perhaps unsurprisingly, people with a pro-social and pro-environmental mindset (voters of green and left parties as well as people with a leftist or very leftist political orientation) are most likely to be positive towards both welfare and climate policies. Voters of communist parties express very strong support for welfare policies but less agreement with climate policies. They are, however, still located in the area of synergy. The same applies to voters of protest and religious parties. It is a for the time being an open question whether or not ideological differences vis-à-vis moderate leftist as well as green movements can be bridged in the future to forge a larger eco-social alliance. Voters of more moderate social-democratic parties are closer to the center of the map but still within an area that would allow for pursuing an eco-social policy strategy across parties. On the opposite side, in the lower regions of the map, where the rejection of welfare policies is associated with support of fossil energy and the rejection of climate mitigation policies, we find the respondents with conservative and, particularly, right-wing populist views. Finally, high degrees of social trust and a universalistic mindset appear in the area of synergy, while low trust is associated with crowding-out. The absence of universalism is linked to a total rejection of both climate and welfare policies. 


\section{Discussion}

The emerging concept of sustainable welfare attempts to integrate environmental sustainability and social welfare research. Oriented at a mid-term re-embedding of production and consumption norms into planetary limits, it suggests the development and implementation of "eco-social" policies in the rich countries. In this article, we set out to explore the attitudes of people in 23 countries on climate and welfare policies as to whether these converge or diverge: "Crowding out" vs. "double worry/synergy" [27] or neither of the two. We were also interested in the influence of welfare regime affiliation and a range of socio-demographic and political factors on people's views on combining welfare and climate policy goals.

The maps resulting from the MCA revealed three main patterns of a relationship between welfare and climate policies: 1 . Both policies are rejected; 2 . There is support for both kinds of policies (synergy); 3 . There is support for welfare but not for climate policies (crowding-out). The countries" positions in the MCA map followed welfare regime lines to a significant extent and partially confirmed the hypothesis that attitudes in countries of social-democratic welfare regime affiliation are most supportive of sustainable welfare and eco-social policies [9] (pp. 325-360). However, the fact that people in Belgium, Switzerland, and Germany (all of conservative welfare affiliation) expressed the same amount of simultaneous support for welfare and climate policies indicated that there are also other institutional factors than welfare regimes at play that should be studied further. Mediterranean countries such as Spain, Italy and Portugal, whose citizens have likewise turned out to be rather supportive of eco-social policy strategies, seem to be especially interesting cases for such further study, given the fact that these countries also feature a superior "objective" environmental performance (measured as ecological footprints and carbon emissions) as compared to the Nordic countries [12,30]. Conversely, people in liberal countries such as the UK and Ireland but also in Eastern European countries such as Poland and Czech Republic were least positive towards sustainable welfare. People in Israel, Hungary, and Lithuania shared a pattern of "crowding out" that we labeled "fossil welfare".

Our comparative analysis has further indicated the pattern that public opinions tend to reflect and reinforce existing structural conditions of energy supply: People in countries with an already advanced production of renewable energy wish to further invest in renewable energies, while citizens of countries that predominantly use fossil energies seem to be satisfied with the existing energy mix and/or worry about the socio-economic consequences of a transition towards environmental sustainability. The observation that attitudes on sustainable welfare varied with the nature of the energy basis calls for state energy and decarbonization policy strategies that are oriented at the mid-term and not at short-term electoral gains. There is, hence, a structural potential for initiating and accelerating a virtuous policy circle involving moves towards renewable energy sources and eco-social policies that policymakers could make more use of.

The analysis of the links between socio-demographic and political factors and attitudes towards social and climate policies has pointed to strong associations of education and universalistic value orientations to sustainable welfare and eco-social policies. This finding suggests that public information and educational policies that focus on the links between social and environmental issues could increase support for climate mitigation measures and sustainable welfare. The fact that "socio-cultural professionals" turned out to be the only class that currently supports climate and welfare policies at the same time is an interesting finding which recently also appeared in a study about eco-social attitudes of the German population [45]. According to Oesch [42], socio-cultural professionals and semi-professionals are persons who have jobs that follow an interpersonal work logic. Those jobs are prevalent in the care sector as well as in child and academic education - traditionally female-dominated occupations. However, since we found gender not varying with attitudes towards sustainable welfare, it seems very likely that socio-cultural professionals are more in favour of sustainable welfare than others because of the interpersonal work logic that involves responsibility for others, empathy, and mutual support. In contrast, large employers expressed the most negative views on sustainable welfare. Their work logic is dominated by economic cost-benefit calculations-a reasoning that is often in 
opposition to social and environmental values. Further research could take a deeper look at the role of work logic and also include, for example, persons who are not employed but busied with working in the household and caring for children.

The most significant factors for the convergence of welfare and climate attitudes were respondents political positions, where, perhaps unsurprisingly, voters of green and moderate left parties displayed the highest values. While a political alliance to put forward eco-social policies between voters of left, green and social-democratic parties appears at least possible, this looks much less realistic in relation to supporters of conservative and right-wing populist parties, who tend to reject state initiatives altogether, that is, in both areas, welfare, and climate protection. The finding that Muslims display a relatively high degree of "synergy" in relation to climate and welfare attitudes came as a surprise to us and merits further study. Future research could, for example, explore the link between the social status of Muslims and their attitudes towards sustainable welfare.

Though attitudes in countries with social-democratic regime affiliation turned out to be among the most "progressive" concerning the simultaneous support of welfare and climate policies, previous studies showed that the actual environmental performances of these countries were not better than that of other industrialized countries $[12,30,31]$. These studies rather indicated a strong link between the level of economic development measured in GDP per capita, that is, irrespective of welfare regime affiliation, and environmental performance. In fact, one of the countries whose citizens here revealed very positive views on a conversion of environmental and social policies-Norway-belongs at the same time to a group of countries that we previously referred to as "over-developed" [12], since GDP, ecological footprint and carbon emissions per capita are among the highest on the planet.

On the one hand, it seems to follow from this contradiction of environmental performance and "eco-social" attitudes that the atmosphere cannot "wait" for the end of an environmental modernist cycle, where progressive attitudes towards sustainable welfare and eco-social policies may begin to take root at a very high level of economic development: If all countries were to emulate the trajectory that led to the current production and consumption patterns of industrialized Western countries such as Norway before their electorates are prepared to accept effective eco-social policies, the combat against the climate crisis were indeed lost.

On the other hand, our results indicate that the potential for providing eco-social policies and sustainable welfare in the rich countries is far from exhausted. Since significant shares of citizens are prepared and approve, in principle, of carrying out climate and welfare policies in combination, policymakers could become bolder in initiating and furthering an ecological and social transition than currently is the case.

Further empirical research on sustainable welfare could focus on directly measuring attitudes towards an integrated eco-social policy instead of combining opinions on both environmental and social policy a posteriori. It would also enhance our understanding of sustainable welfare if succeeding studies would broaden the perspective from climate-related issues to other and more general environmental topics. Finally, the inclusion of countries from other World regions, particularly from the global South, would complement our picture of how people think about sustainable welfare and of the differences that occur in varying socio-economic contexts.

More research with different data and new empirical studies are necessary to advance analyses on sustainable welfare further and to answer the critical question of how far the approval for sustainable welfare expressed by citizens of the rich countries goes in practice-in particular, whether this includes the questioning of own material welfare levels and lifestyles.

Author Contributions: Conceptualization, M.F. and M.K.; methodology, M.F. and M.K.; data analysis, M.F.; theoretical discussion, M.K.; writing—original draft preparation, M.F. and M.K.; writing—review and editing, M.F. and M.K.

Funding: During the production of this article Martin Fritz was supported by the Bielefeld Young Researchers Fund of the University of Bielefeld, Germany. Max Koch acknowledges that his contribution benefited from funding from the FORMAS (Swedish Research Council FORMAS) project The New Urban Challenge: Models of Sustainable Welfare in Swedish Metropolitan Cities (grant no. 2016-00340). 
Acknowledgments: We thank four anonymous reviewers for their helpful and constructive comments.

Conflicts of Interest: The authors declare no conflict of interest.

\section{References}

1. Roberts, J.T.; Parks, B.C. A Climate of Injustice. Global Inequality, North-South Politics, and Climate Policy; MIT Press: Cambridge, UK, 2006.

2. Walker, G. Environmental Justice: Concepts, Evidence and Politics; Routledge: London, UK, 2012.

3. Gough, I. Carbon mitigation policies, distributional dilemmas and social policies. J. Soc. Policy 2013, 42, 191-213. [CrossRef]

4. Büchs, M.; Bardsley, N.; Duwe, S. Who bears the brunt? Distributional effects of climate change mitigation policies. Crit. Soc. Policy 2011, 31, 285-307. [CrossRef]

5. Gough, I.; Meadowcroft, J. Decarbonising the welfare state. In Oxford Handbook of Climate Change and Governance; Dryzek, J., Noorgaard, R., Schlosberg, D., Eds.; Oxford University Press: Oxford, UK, 2011; pp. 490-503.

6. Koch, M.; Mont, O. (Eds.) Sustainability and the Political Economy of Welfare; Routledge: London, UK, 2016.

7. Gough, I. Heat, Greed and Human Need. Climate Change, Capitalism and Sustainable Wellbeing; Edward Elgar: Cheltenham, UK, 2017.

8. Pye, S.; Skinner, I.; Meyer-Ohlendorf, N.; Leipprand, A.; Lucas, K.; Salmons, R. Addressing the Social Dimensions of Environmental Policy; Unit E1-Social and Demographic Analysis, DG Employment, Social Affairs and Equal Opportunities; European Commission: Brussels, Belgium, 2008.

9. Gough, I.; Meadowcroft, J.; Dryzek, J.; Gerhards, J.; Lengfeld, M.; Markandya, A.; Ortiz, R. Climate Change and Social Policy. J. Eur. Soc. Policy 2008, 18, 325-344. [CrossRef]

10. Meadows, D.H.; Meadows, D.L.; Randers, J.; Behrens, W.W. Limits to Growth: A Report for the Club of Rome's Project on the Predicament of Mankind; Universe Books: New York, NY, USA, 1972.

11. Schoyen, M.; Hvinden, B. Climate Change as a Challenge for European Welfare States. In Handbook of European Social Policy; Kenneth, P., Lendvai-Bainton, N., Eds.; Edward Elgar: Cheltenham, UK, 2017; pp. 371-385.

12. Fritz, M.; Koch, M. Economic Development and Prosperity Patterns around the World: Structural Challenges for a Global Steady-state Economy. Glob. Environ. Chang. 2016, 38, 41-48. [CrossRef]

13. O'Neill, D.W.; Fanning, A.L.; Lamb, W.F.; Steinberger, J.K. A Good Life for All Within Planetary Boundaries. Nat. Sustain. 2018, 1, 88-95. [CrossRef]

14. Fitzpatrick, T. Understanding the Environment and Social Policy; Policy Press: Bristol, UK, 2011.

15. Brandstedt, E.; Emmelin, M. The concept of sustainable welfare. In Sustainability and the Political Economy of Welfare; Koch, M., Mont, O., Eds.; Routledge: London, UK, 2016; pp. 15-28.

16. Langhelle, O. Sustainable Development: Exploring the Ethics of our Common Future. Int. Political Sci. Rev. 1999, 20, 129-149. [CrossRef]

17. Koch, M.; Buch-Hansen, H.; Fritz, M. Shifting Priorities in Degrowth Research: An Argument for the Centrality of Human Needs. Ecol. Econ. 2017, 138, 74-81. [CrossRef]

18. Koch, M.; Buch-Hansen, H. Human needs, steady-state economics and sustainable welfare. In Sustainability and the Political Economy of Welfare; Koch, M., Mont, O., Eds.; Routledge: London, UK, 2016; pp. $29-43$.

19. Weiss, M.; Cattaneo, S. Degrowth-Taking Stock and Reviewing and Emerging Academic Paradigm. Ecol. Econ. 2017, 137, 220-230. [CrossRef] [PubMed]

20. Cosme, I.; dos Santos, R.F.; O'Neill, D. Assessing the Degrowth Discourse: A Review and Analysis of Academic Degrowth Proposals. J. Clean. Prod. 2017, 149, 321-334. [CrossRef]

21. Büchs, M.; Koch, M. Challenges for the Degrowth Transition: The Debate about Wellbeing. Futures 2019, 105, 155-165. [CrossRef]

22. Büchs, M.; Koch, M. Postgrowth and Wellbeing: Challenges to Sustainable Welfare; Palgrave Macmillan: Basingstoke, UK, 2017.

23. Daly, H.; Farley, J. Ecological Economics. Principles and Applications; Island Press: Washington, UK, 2011.

24. Jackson, T. Prosperity without Growth: Economics for a Future Planet; Routledge: London, UK, 2011.

25. Steffen, W.; Richardson, K.; Rockström, J.; Cornell, S.E.; Fetzer, I.; Bennett, E.M.; Biggs, R.; Carpenter, S.R.; de Vries, W.; de Wit, C.A.; et al. Planetary Boundaries: Guiding Human Development on a Changing Planet. Science 2015, 347, 6223. [CrossRef] [PubMed] 
26. Incoprera, F.C. Climate Change: A Wicked Problem. Complexity and Uncertainty at the Intersection of Science, Economics, Politics, and Human Behavior; Cambridge University Press: New York, NY, USA, 2015.

27. Jakobsson, N.; Muttarak, R.; Schoyen, M. Dividing the Pie in the Eco-social State: Exploring the Relationship Between Public Support for Environmental and Welfare Policies. Environ. Plan. C Politics Space 2017, 36, 313-339. [CrossRef]

28. Esping-Andersen, G. The Three Worlds of Welfare Capitalism; Polity Press: Cambridge, UK, 1990.

29. Arts, W.; Gelissen, J. Three Worlds of Welfare Capitalism or More? A State-of-the-art Report. J. Eur. Soc. Policy 2012, 12, 137-158. [CrossRef]

30. Koch, M.; Fritz, M. Building the Eco-social State: Do Welfare Regimes Matter? J. Soc. Policy 2014, 43, 679-703. [CrossRef]

31. Duit, A. The four faces of the environmental state: Environmental governance regimes in 28 countries. Environ. Politics 2017, 25, 69-91. [CrossRef]

32. ESS Round 8: European Social Survey Round 8 Data; Data File edition 2.0; NSD-Norwegian Centre for Research Data, Norway-Data Archive and distributor of ESS data for ESS ERIC: Bergen, Norway, 2016.

33. European Social Survey. ESS Round 8 Source Questionnaire; ESS ERIC Headquarters c/o City University London: London, UK, 2016.

34. Bourdieu, P. Distinction: A Social Critique of the Judgment of Taste; Harvard University Press: Cambridge, MA, USA, 1984.

35. Benzécri, J.-P. L"Analyse des Données: L"Analyse des Correspondances; Dunod: Paris, France, 1973.

36. Ferragina, E.; Seeleib-Kaiser, M.; Tomlinson, M. Unemployment Protection and Family Policy at the Turn of the 21st Century: A Dynamic Approach to Welfare Regime Theory. Soc. Policy Adm. 2013, 47, 783-805. [CrossRef]

37. Fritz, M.; Koch, M. Potentials for prosperity without growth: Ecological sustainability, social inclusion and the quality of life in 38 countries. Ecol. Econ. 2014, 108, 191-199. [CrossRef]

38. Blasius, J.; Greenacre, M. Multiple correspondence analysis and related methods in practice. In Multiple Correspondence Analysis and Related Methods; Greenacre, M., Blasius, J., Eds.; Chapman and Hall: Boca Raton, FL, USA, 2016; pp. 3-40.

39. Greenacre, M. From Simple to Multiple Correspondence Analysis. In Multiple Correspondence Analysis and Related Methods; Greenacre, M., Blasius, J., Eds.; Chapman and Hall: Boca Raton, FL, USA, 2016; pp. 41-76.

40. OECD Online Tool-Compare Your Country. Climate Change Mitigation Policies. Available online: https: //www.compareyourcountry.org/climate-policies (accessed on 17 July 2019).

41. European Labour Force Survey. Ifsa_egan22d. Available online: https://ec.europa.eu/eurostat/web/lfs/data/ database (accessed on 17 July 2019).

42. Oesch, D. Coming to Grips with a Changing Class Structure. An Analysis of Employment Stratification in Britain, Germany, Sweden and Switzerland. Int. Sociol. 2006, 21, 263-288. [CrossRef]

43. Armingeon, K.; Wenger, V.; Wiedemeier, F.; Isler, C.; Knöpfel, L.; Weisstanner, D.; Engler, S. Codebook: Comparative Political Data Set 1960-2015; Institute of Political Science, University of Bern: Bern, Switzerland, 2017.

44. Schwartz, S.H. An Overview of the Schwartz Theory of Basic Values. Online Read. Psychol. Cult. $2012,2,11$. [CrossRef]

45. Eversberg, D. Who can challenge the imperial mode of living? The terrain of struggles for social-ecological transformation in the German population. Innov. Eur. J. Soc. Sci. Res. 2019. forthcoming.

(C) 2019 by the authors. Licensee MDPI, Basel, Switzerland. This article is an open access article distributed under the terms and conditions of the Creative Commons Attribution (CC BY) license (http://creativecommons.org/licenses/by/4.0/). 